Portland State University

PDXScholar

Engineering and Technology Management

Faculty Publications and Presentations

9-1-2016

\title{
A Hierarchical Decision Model (HDM) for Exploring the Adoption of Electronic Health Records
}

\author{
Caroline Mudavadi \\ Portland State University \\ Liliya Hogaboam \\ Portland State University \\ Tugrul Unsal Daim \\ Portland State University, tugrul@etm.pdx.edu
}

Follow this and additional works at: https://pdxscholar.library.pdx.edu/etm_fac

Part of the Operations Research, Systems Engineering and Industrial Engineering Commons Let us know how access to this document benefits you.

\section{Citation Details}

Mudavadi, Caroline; Hogaboam, Liliya; and Daim, Tugrul Unsal, "A Hierarchical Decision Model (HDM) for Exploring the Adoption of Electronic Health Records" (2016). Engineering and Technology Management Faculty Publications and Presentations. 109.

https://pdxscholar.library.pdx.edu/etm_fac/109

This Article is brought to you for free and open access. It has been accepted for inclusion in Engineering and Technology Management Faculty Publications and Presentations by an authorized administrator of PDXScholar. Please contact us if we can make this document more accessible: pdxscholar@pdx.edu. 


\title{
A Hierarchical Decision Model (HDM) for Exploring the Adoption of Electronic Health Records
}

\author{
Caroline Mudavadi, Liliya Hogaboam, Tugrul U. Daim \\ Dept. of Engineering and Technology Management, Portland State University, OR - USA
}

\begin{abstract}
Information systems have been making a noticeable entrance in the healthcare, although their adoption has been slow. This paper examines the factors influencing the electronic healthcare records (EHR) adoption by modeling behavioral intention of physicians towards EHR adoption. Three main criteria: perceived usefulness, perceived ease of use and external factors along with the subcriteria, are studied by the authors. Analytical hierarchical process (AHP) model is tested through the expert judgment quantification of physicians in Portland metro area. The results showed high importance of the Perceived Ease of Use criteria on the behavioral intensions of physicians towards EHR adoption. Search ability and user interface - subcriteria of Perceived Ease of Use had some of the highest values. Another important subcriterion in the analysis under External Factors Criteria was Cost. None of the criteria evaluated could be considered unimportant, i.e. having really low values after the analysis. The results indicate that EHR should be mandatory in terms of reducing of time spent and errors, improving the outcomes and productivity and in terms of optimum patient treatment.
\end{abstract}

\section{INTRODUCTION}

In our modern world where the impact of technology is felt everywhere, information systems are making more noticeable entrance and impact in healthcare. Everybody would agree that e-mail, internet, mobile phone, videoconferencing etc. have changed our lives and made us more connected than ever before. In our everyday lives we have become used to information systems conveniences, while in other industries the adoption process is still ongoing and taking a while. What would be the main reasons for challenges? What are the challenges? What could we do that would help us better understand the adoption barriers in healthcare? How could we help? Those are some of the questions that we try to answer in this paper.

Information management frameworks have the purpose of structuring information flow and its transformation in a certain department in order to ease the flow and delivery of information as well as its improving information utilization for patient care and safety, quality, research, administration and education [1]. Electronic health records (EHR) adoption, examined in this paper, should utilize the modern technology to deliver applications, tools and resources to its users (administrators, doctors and patients) over the internet or intranet networks for the purposes of providing healthcare [2]. EHR is a collection of health information and data, combined with results management, order entry management and decision support [3].

Since this concerns caring for people's lives, there are various security policies and privacy rules that would create challenges for quick implementation of EHR systems in hospitals and clinics. Access and manipulation of information has to be secure and aimed at providing quality healthcare. According to the Health System Change 2008 Health Tracking Physician Survey, with input from 4,700 physicians (62 percent response rate), only 23.8 percent of physicians reported having a complete electronic record system and 26.9 percent had part electronic-part paper one [3]. Some main concerns listed were getting physicians on board, training systems, loss of productivity, financial and regulatory challenges [4], [3]. These and other concerns create certain hesitation and resistance of physicians to adoption of EHR in their practices. In another more recent survey by an independent party - Medical Group Management Association - about 52.3 percent replied that they used EHR, while 35.8 percent still stored records and charts on paper [5]. Of those who replied that they had EHRs, only 16.3 percent completed implementation and believed that their practice optimized the use of EHRs, while 46.3 percent completed implementation and are focusing on optimizing it, 23.8 percent are in the process of implementing EHR systems, 8.2 percent are using EHR and considering switching to a different EHR system, and 5.4 percent have other variation of completed EHR implementation [5]. Results of both surveys show the reality of EHR system adoption in healthcare.

In a recent study Hsiao et al. [6], found that the percentage of office-based physicians with fully functional EHR system was really low in $2009-6.9$ percent and projected to 10.1 percent in 2010.

Misaligned incentives are another reason seen to be an issue, since benefits of healthcare information systems may not contribute enough or at first to efficiency in offices and therefore may not be attractive for the physicians [7]. The major benefactors appear to be payers, as opposed to potential investors [8], [9]. Looking from the perspective of the user would be a logical way to understand the reasons for slow adoption.

In this paper the authors will examine the perceived understanding of the EHR system by a specific group of users - doctors and nurses- and evaluate their perceived usefulness, perceived ease of use and external factors that impact their decisions to adopt of EHR systems.

\section{LITERATURE REVIEW}

\section{A. Information Systems Adoption Theories}

Adoption and diffusion theories have been distinguished as micro- versus macro-perspective approaches respectively; where adoption theory examines how an individual makes choices to accept or reject a particular innovation, diffusion 
examines how an innovation spreads through a population. However, it must be noted that the adoption process is an inseparable part of the diffusion process [10].

The mostly widely applied diffusion theory is Roger's Innovation Diffusion Theory [11]. Similarly, the most significant adoption models include the Theory of Reasoned Action [12], the Theory of Planned Behavior [12], the Technology Acceptance Model [13], [14], Technology Acceptance Model 2 [15] and the Unified Theory of Acceptance and Use of Technology [16].

\section{The Theory of Reasoned Action (TRA)}

This theory was developed by Martin Fishbein and Icek Ajzen in 1975 [12]. The theory states that people's intentions are the best guide to their behavior. The suggestion is that a person's actual behavior can be determined by considering his/her prior intention along with the beliefs that the person will have for the given behavior. Behavioral intention is determined by considering the attitude a person has towards the actual behavior and the subjective norm (the perception that most people important to the individual should or should not perform this behavior) associated with the behavior in question [12].

\section{The Theory of Planned Behavior (TPB)}

Developed by Icek Ajzen in 1991, this theory extended the TRA by taking into account that not all behavior is under volitional control. The TRA states that an individual's behavioral intentions are a function of and his/her attitude toward the behavior and the subjective norms associated with performance of the behavior. The TPB adds a third factor so that in addition to the two behavioral intention determinants, there is a third - perceived behavioral control (the individual's perception of the ease with which the behavior can be performed). Behaviors are considered to be located on a continuum extending from complete control to complete lack of control, with control factors being both internal and external to an individual.

\section{Unified Theory of Acceptance and Use of Technology (UTAUT)}

Proposed by Venkatesh et al, UTAUT aims to explain user intentions to use an information system and subsequent usage behavior. The theory states that there are four direct determinants of usage intention and behavior - performance expectancy, effort expectancy, social influence and facilitating conditions. Additionally the theory proposes that gender, age, experience and voluntariness of use mediate the impact of the above determinants [16]. UTAUT was developed out of eight models that earlier research had applied to explain information system usage behavior (TRA, TAM, motivational model, TPB, combined TPB/TAM model, model of PC utilization, innovation diffusion theory and social cognitive theory). UTAUT was subsequently found to account for 70 percent of variance in usage intention in a longitudinal study [16].

\section{Roger's Innovation Diffusion Theory}

Roger's defined diffusion as a special form of communication where ideas are spread from one individual to another over time. Individuals are seen as possessing different degrees of willingness to adopt innovations. Based in this and a normal distribution of innovation adoption over time, individuals in a population are categorized in terms innovativeness - innovators, early adopters, early majority, late majority, laggards. Laggards are the last demographic to adopt a technology while innovators are the first. Members of each category typically possess distinguishing characteristics. The rate of adoption of innovations is influenced by relative advantage, compatibility, trialability, observability and complexity. The first four factors tend to be positively correlated with the rate of adoption while complexity is generally negatively correlated with the rate of adoption. The actual rate of adoption is governed by the rate at which an innovation takes off as well as the rate of later growth [11].

\section{Technology Acceptance Model (TAM)}

Fred Davis proposed TAM in his doctoral thesis in 1986 as an extension of the TRA. It has since become one of the most influential extensions of the TRA in literature, having been used extensively to study user acceptance and use of technology adoption [17]. TAM focuses on perceived usefulness and perceived ease of use as predictors of individual acceptance or rejection of technology.

Although all the previously highlighted technology adoption theories have their merits, the authors concluded that, due its influence and maturity in studying information technology adoption, TAM would be a good preliminary model to apply.

\section{B. EHR-Background}

According to the Health Information Management Systems Society (HIMSS), "the electronic health record (EHR) is a longitudinal electronic record of patient health information generated by one or more encounters in any care delivery setting" (HIMSS). The term electronic health record (EHR) is synonymous with Electronic Patient Record (EPR), Computerized Patient Record (CPR), Electronic Health Care Record (EHCR), Virtual EHR, Digital Medial Record (DMR), Automated Medical Record, Provider-Based Patient Medical Record and Electronic Medical Record [18].

The purpose of a patient record is to recall observations, to inform others, to instruct students, to gain knowledge, to monitor performance and to justify interventions [19] and to ultimately further the application of health sciences in ways that improve the well-being of patients [20]. The first known medical record was developed by Hippocrates in the fifth century B.C. and he prescribed two goals for such a record; to accurately reflect the course of a disease and to indicate the probable cause of disease [21]. These goals are still appropriate today [22]. Studies observing physicians' use of the paper-based record find that logistical, organizational and other practical limitations reduce the effectiveness of 
traditional records for storing and organizing an everincreasing number of diverse data. An EHR is designed to overcome many of these limitations and provide additional benefits that cannot be attained from a static view of events [20].

EHR adoption is an important issue because firstly, many institutions would like to have EHRs in order to solve the logistic problem of the paper chart - cannot find the record, cannot find the particular items of information that are within it, cannot read it. Secondly, adopting EHRs can solve the problem in multi-site organizations where there is no way to move a paper chart to the multiple sites that require it. Thirdly, EHRs can provide aggregate information about patients for clinical research, outcomes management, process improvement and the development of new care products. Finally, EHR adoption will save money on paper storage, filing costs, and time spent on searching for physical records [23], [24]. Overall, EHR adoption is seen worldwide as one method to reduce the widening gap between health care demand and supply [25].

Nevertheless, despite all the potential benefits of EHRs, there has been some resistance to their adoption. The reason is twofold. Firstly, the sources of electronic patient information that do exist reside on many isolated islands that have been very difficult to bridge. Secondly, experts have not quite figured out how to capture the data from the physician in a structured and computer understandable form and even with a single organization, many separate islands of information exist with different data structures. The external islands differ even more than those within a single institution. In other words, missing standards create interoperability problems [22], [23]. A possible solution to this standardization problem is buying all components from the same vendor but it came to light that these vendors had bought a series of smaller vendors and had not yet integrated disparate applications themselves [23].

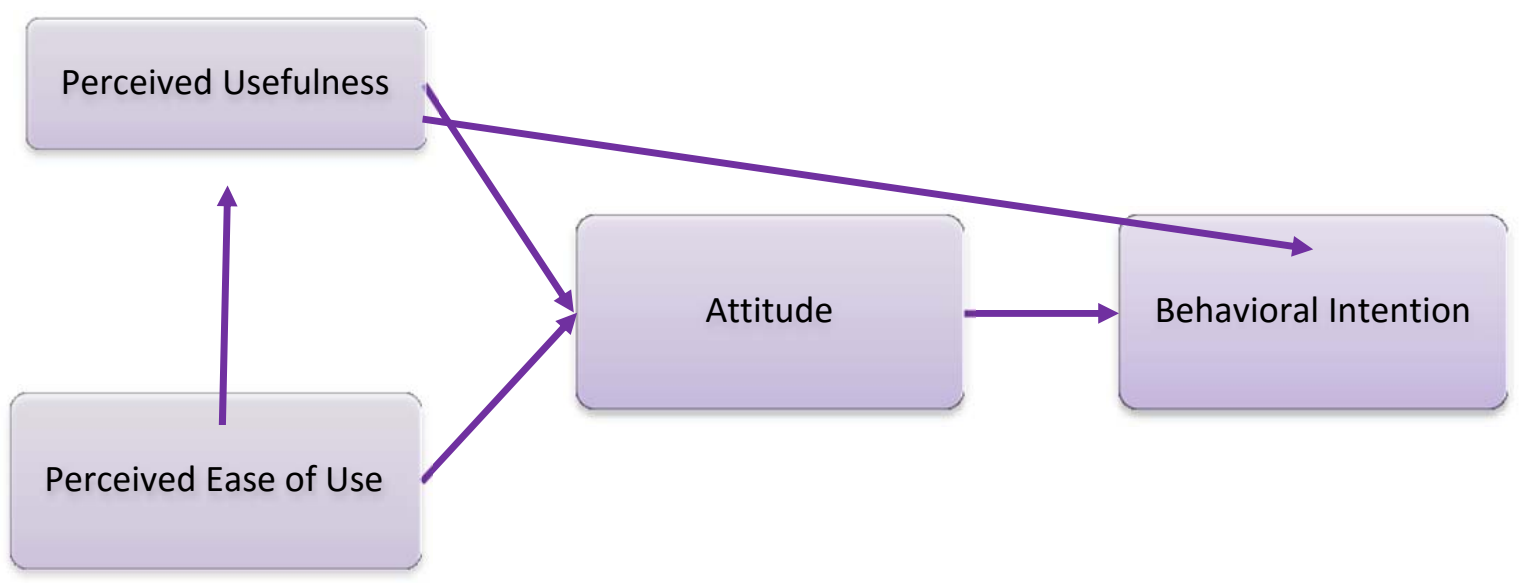

Kok, O., Basoglu, N., \& Daim, T. [26] proposed an EHR adoption model based on the studies of the Technology Acceptance model (TAM), and several other models.

TAM, proposed by Davis in 1989 [27], is one of the most commonly used models to analyze the adoption of information technologies. Information technology, depending on its type, aims to improve users' performances, optimize the use of resources and maximize the outcome benefits. However, experience shows that not every technology will be easily accepted by users. Researchers have addressed this issue by trying to understand users' behavior intentions: What drives them to use certain technology? Davis illustrated in the TAM model (Figure 1) that user motivations were perceived usefulness and perceived ease of use. Perceived usefulness refers to how the technology can help users improve their work performance. Perceived ease of use, on the other hand, represents how easily the technology can be used or operated by users. Perceptibly, users want the operations as simple as possible since it will save them time and enable them to be more productive. Therefore, perceived ease of use will, to some extent, also have an impact on perceived usefulness. Later on, research defined several factors that would impact perceived usefulness and perceived ease of use, such as social impact, job relevance, gender, image, subjective norm, among others [27], [28].

The EHR model proposed by Kok, O., Basoglu, N., \& Daim, T. in 2011 indicated that perceived usefulness, perceived ease of use and external factors are the motivators for the intention to adopt. According to the model in figure 2, perceived usefulness is mainly influenced by quality of care, sharing, medical history and time saving. While, archiving, search ability, user interface and data preservation have significant effects on the perceived ease of use. As mentioned before, ease of use can also improve the usefulness of EHR systems towards users. External factors in their study included the legal influence and international standards issues. The following is the explanation of these factors [26].

Figure 1: Technology Acceptance Model [27] 


\section{A. Factors impacting Perceived Usefulness}

Quality of care: As one of the purposes for developing EHR system, quality of care is always a major concern for healthcare providers including physicians, nurses, administrators, and staff related to the system. Therefore, naturally, the ability of EHR systems to improve the quality of health care has a positive effect on the perceived usefulness, which is also proved by many studies.

Sharing: In order to provide better patient care, physicians need to exchange their recorded information with others, which is also one convenience offered by EHR system. Therefore, speed, ease and more accuracy when sharing health records are the targets for an organization to improve their job performance. Standardization can enhance sharing. Additionally, according to our gap analysis, we found that people are also concerned about the privacy and security within the sharing process.

Medical History: Medical history records the detailed patients' health care information. This keeps physicians informed on patients' history and will, thus, enable them give more accurate and more effective treatment to patients. More detailed and accurate medical history can improve physicians' performance.

Time Saving: The use of computer and advanced technology systems is proven to reduce the time in terms of gathering, viewing and searching the healthcare record information compared to hand-written paper record system. Therefore, the more time is saved, the more useful the EHR system is.

\section{B. Factors impacting Perceived Ease of Use}

Compared to Perceived usefulness, ease of use is mainly from the technical perspective.
Archiving: In health care, archiving is considered as the organized storage of patients' medical data or files [29]. Document management is essential in the EHR system. Patients' medical history assists the health care providers to determine appropriate treatment plans. In order to achieve improved medical care records storage ability, a welldesigned archiving system is key. However, paper record is not a good way for archiving, not only because they are usually handwritten which is generally not legible, but also because old records are easily lost. EHR Systems solve this issue. Taking advantage of computers, users can enter the same information as before without the extra time of worrying about how to store them. Therefore, the more efficient and user-friendly an archiving system is, the more comfortable users will feel to use it [30]

Search Ability: Search ability is another important system characteristic. Easy to find required information is a popular demand by users and is key to increase treatment speed. The accurate information also helps improve treatment performance.

User Interface: Friendly user interface is the key for enabling the system is easy to use for users just like they can write anything they want on a paper sheet. And they can compare and analyze information easily as the way they used to.

Data Preservation: Long-term preservation of recorded information is very important. It prevents inaccessibility and loss of records after a long period of time. Keeping the records can reduce the cost and improve healthcare performance sustainably [26], [29], [31].

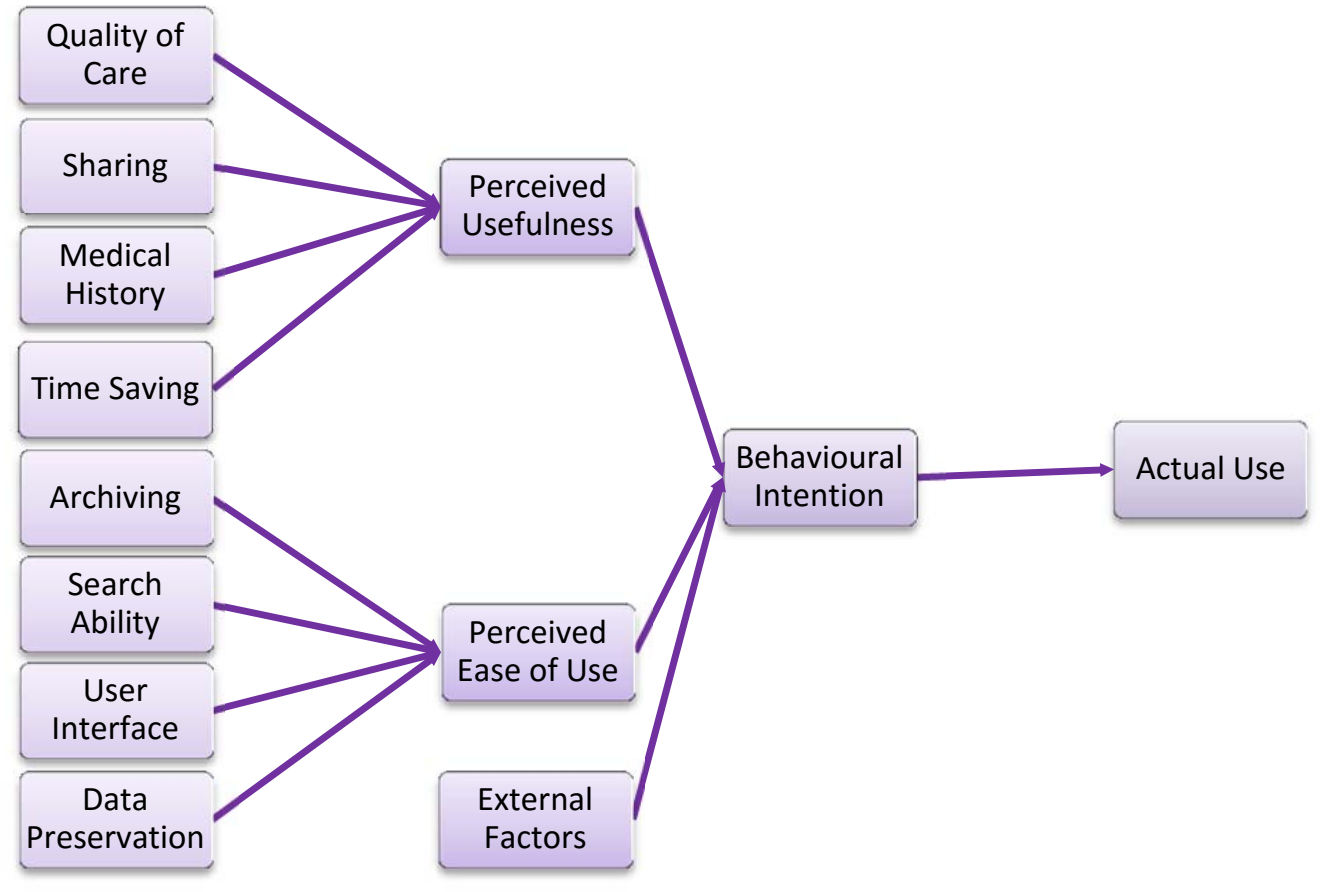

Figure 2: EHR Adoption Model [26] 
The purpose of our study is to analyze the current EHR adoption barriers in Oregon, adapt this model in Oregon EHR adoption and evaluate the model by studying how each factor affects users' decision to adopt EHR systems.

\section{METHODOLOGY}

This paper applies a variation of Saaty's original process. The latter uses eigenvectors where 1-9 measurements are used to compare criteria, sub criteria and alternatives. On the other hand, we use the constant sum method where a total of 100 points are allocated as comparison values in order to arrive at the relative weights of decision elements. The constant sum method was developed by Comrey [32] and Guilford [33] and refined by Kocaoglu [34]. It provides a more precise measurement of data [35].

AHP is one of numerous multi-criteria decision-making methods. Developed by T.L. Saaty, AHP has been described as a general theory of measurement used to derive ratio scales from both discrete and continuous paired comparisons. It is a technique for converting subjective assessments of relative importance into a set of weights [36]. Its most common applications have been as a multi-criteria decision making tool in engineering and the social sector [37]. In AHP a problem is broken down into its constituent elements and structured in the form of a hierarchy depicting a network of relationships with respect to the overall goal [38], [39]. The problem is modeled in a hierarchical structure consisting of goal, objectives (criteria), sub objectives (sub criteria) and alternatives from top to bottom in that order [35], [40]. Using pairwise comparison judgments, the AHP process integrates criteria contribution and alternative preferences measures into a single overall score for ranking decision alternatives [41]. However, AHP does not involve a survey; rather, expert judgment quantification is carried out. In previous studies applying AHP, the number of experts involved in judgment quantification has been between 6 and 12 [26], [40], [42].

Saaty [43] asserts that AHP consists of three principles decomposition, comparative judgment and priority synthesis: Firstly, decomposition involves modeling the problem in the form of a hierarchy, with the highest level representing the overall objective or goal; the middle level(s) representing the evaluation criteria and sub criteria; and the bottommost level representing the decision alternatives. Secondly, comparative judgment refers to pairwise comparison of factors at each level to measure their relative contribution to the overall objective. In comparing pairs of criteria, sub criteria or alternatives, a comparison matrix is developed. This comparison helps decision makers establish the relative contribution of each factor at each level to the objective. Thirdly, priority synthesis computes a composite weight for each alternative based on preferences identified through the comparison matrix. Using the composite weight, relative priority is assigned to each alternative [40]. Bertolini [38] describes the same process in two main phases as follows: The first phase is hierarchy tree definition and represents decomposition as previously described. The second phase is numerical evaluation of the tree and is a combination of

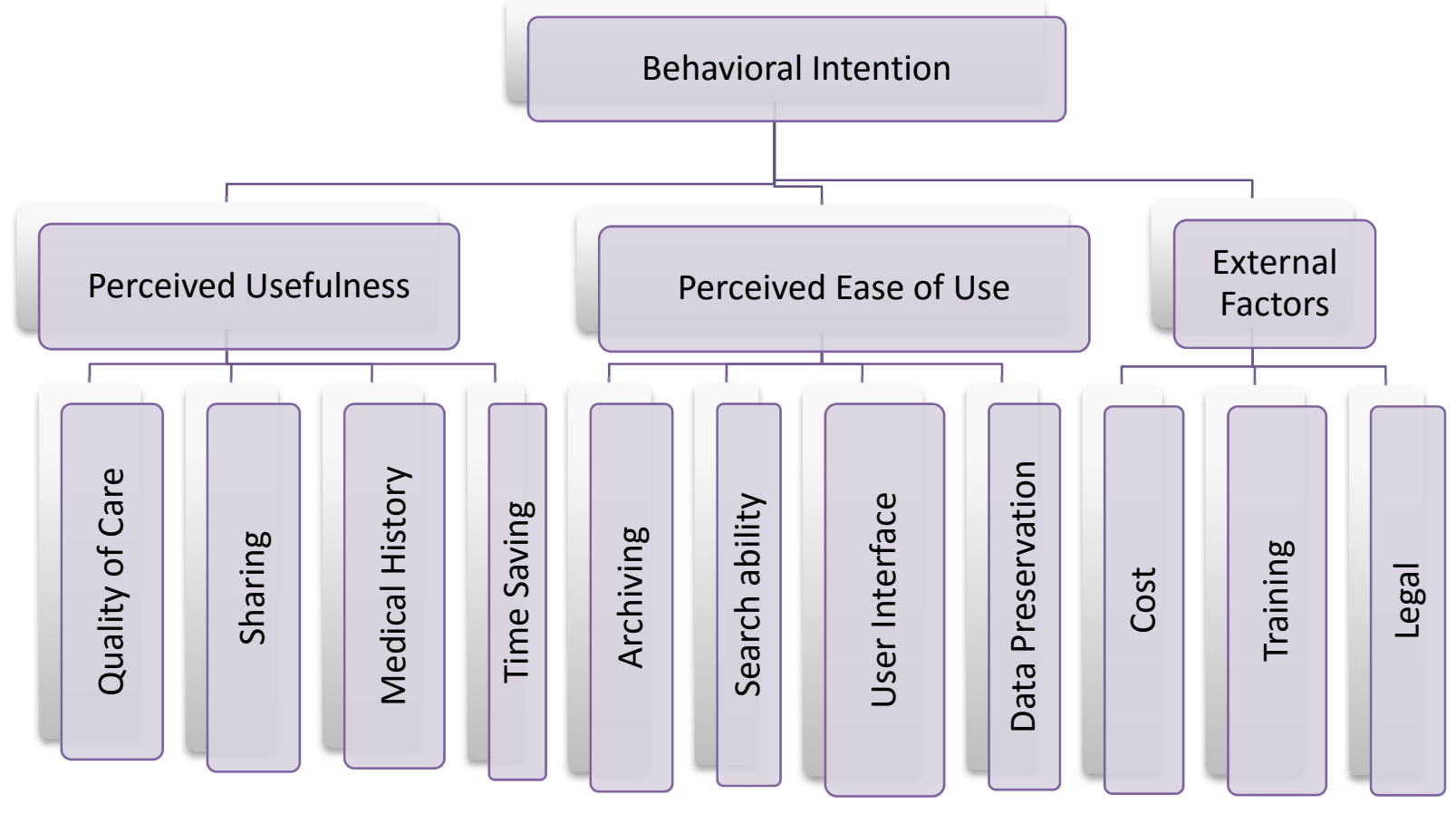

Figure 3: AHP Model 
comparative judgment and priority synthesis as described above. Inconsistency of the results, as filled out by the experts, is calculated in the AHP process and a value of less than 10 percent is considered acceptable to interpret results [34], [44].

AHP has been known to enhance the evaluation, choice and resource allocation phase of decision making because it effectively measures the relative impact of factors affecting possible outcome and thus predicts outcomes. These predictions are useful inputs for evaluating alternative courses of action [40]. The AHP method has been successfully applied to resolve various IS problems such as project selection [45], diagnostic technology [44], manufacturing systems [46] and telecommunication systems vendors [47] among many others. It provides an overarching view of the complex relationship inherent in a problem and helps the decision maker assess the order of magnitude of the evaluation criteria [40]

Implementation of AHP involved:

1. Structuring the EHR Adoption problem hierarchically as laid out below. This model is based on the Technology Acceptance model described in more detail in the EHR Adoption Model Section above.

2. Development of an online instrument to capture expert judgment with pairwise comparisons. An online data collection tool was used to gather data. For instance, in the sample below of the pairwise comparison for "usefulness" relative to "ease of use", respondents were required to move the slider to the desired point - if moved to the 60 point level then usefulness would be more important relative to usefulness and vice versa. These pairwise comparisons were carried out for each level of the hierarchy comparing each criterion against all its counterparts on the same level.

3. Establishing the criteria considered most important to EHR Adoption: Pairwise comparisons from the experts were used to compute and quantify the model.

\section{ANALYSIS AND DISCUSSION OF THE PROPOSED MODEL}

We worked with 11 experts to quantify the model. The experts comprised a variety of people such as physicians, dentists, a clinic director, a general internist, an acupuncturist, and a practicing dental student. The following table shows the details - age, gender, occupation, years of working experience and years of experience with an EHR system for each respondent.

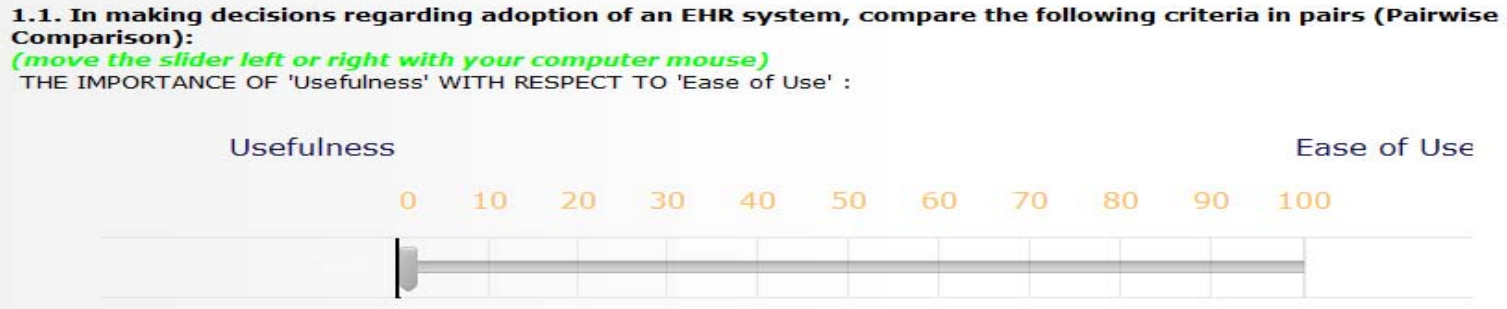

Figure 4: Pairwise Comparison Sample

TABLE 1. RESPONDENTS' GENERAL INFORMATION

\begin{tabular}{|l|l|l|l|l|}
\hline Age & Gender & Occupation & Years of working experlence & Years of experlence with an EHR system \\
\hline 30 's & male & physician & 7 & 3 \\
57 & f & dentist & 35 & 12 \\
31 & Female & Registered Nurse & 7 months & 4 years \\
43 & female & physician & 12 & 12 \\
52 & male & MD & 25 & 5 \\
43 & female & Dentist & 16 & 3 \\
40 & male & acupuncturist & 5 & 2 \\
35 & female & clinic director & 4 & 1 \\
30 & male & student & 2 & $16+$ \\
53 & M & Physician (Internal Med/Hospitalist/lCU) & 25 & 14 \\
41 & female & general internist & 12 & \\
\hline
\end{tabular}


As seen in Table 2, the experts first compared the three main criteria impacting the adoption of EHR: Perceived Usefulness, Perceived of Use, and External Factors among themselves other as below:

1. Perceived Usefulness vs. Ease of Use

2. Perceived Usefulness vs. External Factors

3. Ease of Use vs. External Factors

The relative weights of each factor above are shown in the table 2 .

However, the inconsistency for person 5 (0.327) was high and that resulted in exclusion of that person.

Since Perceived Ease of Use has the highest weight (0.4), it is the most important factor impacting the adoption of
EHR. The following chart (figure 5) shows the percentage distribution of the main factors.

The subcriteria of the three main factors previously mentioned were subsequently compared respectively. Experts first started by comparing the subcriteria of Perceived Usefulness as shown below:

1. Quality of Care vs. Sharing

2. Quality of Care vs. Medical History

3. Quality of Care vs. Medical History

4. Sharing vs. medical History

5. Sharing vs. Time Saving

6. Medical History vs. Time Saving

TABLE 2. ORIGINAL EHR ADOPTION INTENTION WEIGHTS

\begin{tabular}{|c|c|c|c|}
\cline { 2 - 4 } \multicolumn{1}{c|}{} & \multicolumn{3}{c|}{ Original Intention } \\
\cline { 2 - 4 } \multicolumn{1}{c|}{} & Perceived Usefulness & Perceived Ease of Use & External Factors \\
\hline Person 1 & 0.01 & 0.50 & 0.50 \\
\hline Person 2 & 0.56 & 0.31 & 0.13 \\
\hline Person 3 & 0.28 & 0.49 & 0.23 \\
\hline Person 4 & 0.46 & 0.38 & 0.16 \\
\hline Person 5 & 0.21 & 0.47 & 0.32 \\
\hline Person 6 & 0.17 & 0.53 & 0.30 \\
\hline Person 7 & 0.38 & 0.38 & 0.25 \\
\hline Person 8 & 0.40 & 0.45 & 0.14 \\
\hline Person 9 & 0.35 & 0.40 & 0.25 \\
\hline Person 10 & 0.33 & 0.33 & 0.33 \\
\hline Person 11 & 0.35 & 0.25 & 0.40 \\
\hline
\end{tabular}

TABLE 3. ACTUAL EHR ADOPTION INTENTION WEIGHTS

\begin{tabular}{|c|c|c|c|}
\cline { 2 - 4 } \multicolumn{1}{c|}{} & \multicolumn{3}{c|}{ Actual Intention } \\
\cline { 2 - 4 } \multicolumn{1}{c|}{} & Perceived Usefulness & Perceived Ease of Use & External Factors \\
\hline Person 1 & 0.01 & 0.50 & 0.50 \\
\hline Person 2 & 0.56 & 0.31 & 0.13 \\
\hline Person 3 & 0.28 & 0.49 & 0.23 \\
\hline Person 4 & 0.46 & 0.38 & 0.16 \\
\hline Person 6 & 0.17 & 0.53 & 0.30 \\
\hline Person 7 & 0.38 & 0.38 & 0.25 \\
\hline Person 8 & 0.40 & 0.45 & 0.14 \\
\hline Person 9 & 0.35 & 0.40 & 0.25 \\
\hline Person 10 & 0.33 & 0.33 & 0.33 \\
\hline Person 11 & 0.35 & 0.25 & 0.40 \\
\hline
\end{tabular}

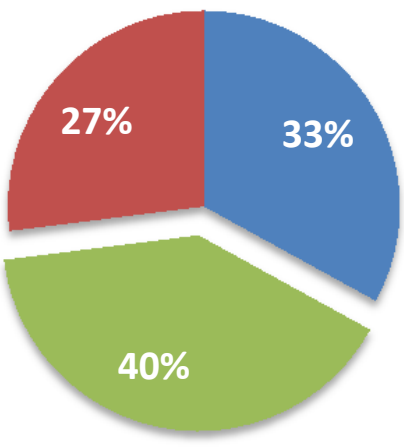

Perceived Usefuness

Perceived Ease of Use

External Factors

Figure 5: The contribution percentages of Usefulness, Ease of Use and External Factors 
After the above comparisons have been made, the first result obtained for the relative weights of each subcriteria is as in the below table. It includes the relative weights of the subcriteria of Perceived Usefulness.

Here, we realized much higher inconsistencies of 0.209 and 0.287 for persons 3 and 5 respectively.

Therefore, the data for persons 3 and 7 were removed. The final results for the subcriteria of Perceived Usefulness are as Table 5 .

Subsequently, the normalized values had to be calculated by multiplying the main criterion (Perceived Usefulness) with each of its sub criteria as in table 6.

Time Saving, by a small margin, got the highest percentage in the 'Perceived Usefulness' category; its score is very close to Quality of Care and Medical History. Medical History (recording patients' health care information) and Quality of Care show equal percentages in importance for
Perceived Usefulness and the authors considered those factors important subcriteria. The distribution didn't show a single factor standing out, since all the weights are between 0.21 and 0.27 . The lowest score was for Sharing but it really was not low enough to discount its importance.

Next, the subcriteria of Perceived Ease of Use were compared as below:

1. Archiving vs. Search Ability

2. Archiving vs. User Interface

3. Archiving vs. Data Preservation

4. Search Ability vs. User Interface

5. Search Ability vs. Data Preservation

6. User Interface vs. Data Preservation

The first results we obtained for the relative weights of the subcriteria of the Perceived Ease of Use factor are shown in table 7 .

TABLE 4. ORIGINAL EHR PERCEIVED USEFULNESS WEIGHTS

\begin{tabular}{|c|c|c|c|c|c|}
\hline & \multicolumn{4}{|c|}{$\begin{array}{l}\text { Original Perceived Usefulness } \\
\end{array}$} & \\
\hline & Quality of Care & Sharing & Medical History & Time Saving & \\
\hline Person 1 & 0.18 & 0.13 & 0.40 & 0.28 & \\
\hline Person 2 & 0.35 & 0.19 & 0.32 & 0.15 & \\
\hline Person 3 & 0.56 & 0.18 & 0.25 & 0.01 & \\
\hline Person 4 & 0.37 & 0.21 & 0.29 & 0.13 & \\
\hline Person 5 & 0.20 & 0.21 & 0.28 & 0.30 & \\
\hline Person 6 & 0.09 & 0.20 & 0.14 & 0.57 & \\
\hline Person 7 & 0.30 & 0.28 & 0.37 & 0.05 & \\
\hline Person 8 & 0.24 & 0.11 & 0.24 & 0.40 & \\
\hline Person 9 & 0.32 & 0.26 & 0.26 & 0.16 & \\
\hline Person 10 & 0.25 & 0.25 & 0.25 & 0.25 & \\
\hline Person 11 & 0.36 & 0.32 & 0.16 & 0.16 & \\
\hline & 0.29 & 0.21 & 0.27 & 0.22 & 1.00 \\
\hline
\end{tabular}

TABLE 5. ACTUAL EHR PERCEIVED USEFULNESS WEIGHTS

\begin{tabular}{|l|c|c|c|c|}
\cline { 2 - 5 } \multicolumn{1}{c|}{} & \multicolumn{3}{c|}{ Actual Perceived Usefulness } & Time Saving \\
\cline { 2 - 5 } \multicolumn{1}{c|}{} & Quality of Care & Sharing & Medical History & 0.28 \\
\hline Person 1 & 0.18 & 0.13 & 0.40 & 0.15 \\
\hline Person 2 & 0.35 & 0.19 & 0.32 & 0.13 \\
\hline Person 4 & 0.37 & 0.21 & 0.29 & 0.30 \\
\hline Person 5 & 0.20 & 0.21 & 0.28 & 0.40 \\
\hline Person 6 & 0.09 & 0.11 & 0.14 & 0.16 \\
\hline Person 8 & 0.24 & 0.26 & 0.24 & 0.25 \\
\hline Person 9 & 0.32 & 0.25 & 0.26 & 0.16 \\
\hline Person 10 & 0.25 & 0.32 & 0.25 & $\mathbf{0 . 2 7}$ \\
\hline Person 11 & 0.36 & $\mathbf{0 . 2 1}$ & 0.16 & $\mathbf{0 . 2 6}$ \\
\hline
\end{tabular}

TABLE 6: FINAL FACTOR WEIGHT RESULTS FOR USEFULNESS SUBCRITERIA

\begin{tabular}{|c|c|c|c|}
\hline Usefulness & Subcriteria Respectively & Results & \\
\hline 0.33 & 0.26 & 0.0858 & Quality of Care \\
\hline 0.33 & 0.21 & 0.0693 & Sharing \\
\hline 0.33 & 0.26 & 0.0858 & Medical History \\
\hline 0.33 & 0.27 & 0.0891 & Time Saving \\
\hline
\end{tabular}


TABLE 7: ORIGINAL EHR PERCEIVED EASE OF USE WEIGHTS

\begin{tabular}{|c|c|c|c|c|}
\cline { 2 - 5 } \multicolumn{1}{c|}{} & \multicolumn{5}{c|}{ Original Ease of Use } & Data Preservation \\
\cline { 2 - 5 } \multicolumn{1}{c|}{} & Archiving & Search Ability & User Interface & 0.25 \\
\hline Person 1 & 0.20 & 0.25 & 0.31 & 0.21 \\
\hline Person 2 & 0.18 & 0.31 & 0.30 & 0.14 \\
\hline Person 3 & 0.36 & 0.45 & 0.05 & 0.16 \\
\hline Person 4 & 0.29 & 0.25 & 0.30 & 0.22 \\
\hline Person 5 & 0.28 & 0.28 & 0.23 & 0.25 \\
\hline Person 6 & 0.22 & 0.25 & 0.28 & 0.01 \\
\hline Person 7 & 0.60 & 0.32 & 0.07 & 0.16 \\
\hline Person 8 & 0.16 & 0.37 & 0.32 & 0.46 \\
\hline Person 9 & 0.18 & 0.16 & 0.20 & 0.25 \\
\hline Person 10 & 0.25 & 0.25 & 0.25 & 0.20 \\
\hline Person 11 & 0.15 & 0.38 & 0.27 & $\mathbf{0 . 2 1}$ \\
\hline
\end{tabular}

TABLE 8: ACTUAL EHR PERCEIVED EASE OF USE WEIGHTS

\begin{tabular}{|c|c|c|c|c|}
\cline { 2 - 5 } \multicolumn{1}{c|}{} & \multicolumn{4}{c|}{ Actual Ease of Use } \\
\cline { 2 - 5 } \multicolumn{1}{c|}{} & Archiving & Search Ability & User Interface & Data Preservation \\
\hline Person 1 & 0.20 & 0.25 & 0.31 & 0.25 \\
\hline Person 2 & 0.18 & 0.31 & 0.30 & 0.21 \\
\hline Person 5 & 0.28 & 0.28 & 0.23 & 0.22 \\
\hline Person 6 & 0.22 & 0.25 & 0.28 & 0.25 \\
\hline Person 8 & 0.16 & 0.37 & 0.32 & 0.16 \\
\hline Person 9 & 0.18 & 0.16 & 0.20 & 0.46 \\
\hline Person 10 & 0.25 & 0.25 & 0.25 & 0.25 \\
\hline Person 11 & 0.15 & 0.38 & 0.27 & 0.20 \\
\hline
\end{tabular}

TABLE 9: FINAL FACTOR WEIGHT RESULTS FOR EASE OF USE SUBCRITERIA

\begin{tabular}{|c|c|c|c|}
\hline Ease of Use & Subcriteria Respectively & Results & \\
\hline 0.40 & 0.20 & 0.0800 & Archiving \\
\hline 0.40 & 0.28 & 0.1120 & Search Ability \\
\hline 0.40 & 0.27 & 0.1080 & User Interface \\
\hline 0.40 & 0.25 & 0.1000 & Data Preservation \\
\hline
\end{tabular}

Similar to previous comparisons, some experts had high inconsistencies and their data were consequently excluded. They were person $3(0.243)$, person $4(0.123)$, and person 7 (0.103).

Table 8 shows the results of the subcriteria of Perceived Ease of Use after removing the high inconsistencies.

As done for the prior subcriteria, the normalized values of the subcriteria of Perceived Ease of Use are calculated using the data in table 9 which also shows the results.

Since three weights of subcriteria are very close to in value, it can be concluded that the experts think that Search ability, User Interface, and Data Preservation are all important to Perceived Ease of Use. In other words, in an EHR system, the experts think that:

1. Finding the required information easily in terms of accurate information and speeding up the treatment

2. Writing anything they want on a paper and comparing/analyzing information easily

3. Preventing from inaccessible and lost records after a long time period and reducing the cost and improving the health care performance by keeping records are more important than Archiving.

TABLE 10: EXTERNAL FACTORS WEIGHTS CALCULATION

\begin{tabular}{|c|c|c|c|c|}
\hline & \multicolumn{3}{|c|}{ External Factors } & \\
\hline & Cost & Training & Legal/Policy & \\
\hline Person 1 & 0.42 & 0.37 & 0.21 & \\
\hline Person 2 & 0.25 & 0.47 & 0.29 & \\
\hline Person 3 & 0.60 & 0.24 & 0.16 & \\
\hline Person 4 & 0.19 & 0.61 & 0.21 & \\
\hline Person 5 & 0.30 & 0.28 & 0.42 & \\
\hline Person 6 & 0.64 & 0.10 & 0.26 & \\
\hline Person 7 & 0.50 & 0.29 & 0.21 & \\
\hline Person 8 & 0.35 & 0.27 & 0.37 & \\
\hline Person 9 & 0.33 & 0.33 & 0.33 & \\
\hline Person 10 & 0.54 & 0.29 & 0.17 & \\
\hline Person 11 & 0.41 & 0.33 & 0.26 & \\
\hline & 0.41 & 0.33 & 0.26 & 1.00 \\
\hline
\end{tabular}


Finally, the subcriteria of External Factors were compared as follows:

1. Cost vs. Legal / Policy

2. Cost vs. Training

3. Legal Policy vs. Training

No high inconsistencies were found for the comparisons within this criterion. Table 10 presents the results.

The same procedure was followed to calculate the normalized values (table 11).

As was expected, Cost is the most important subcriterion of External Factors. This means that according to the experts, Cost (up-front purchase cost, maintenance cost, training cost and upgrading cost) has the highest impact on the adoption of EHR.

The chart in figure 6 shows the percentage distribution of all the subcriteria.

\section{CONCLUSIONS}

Results indicate that, Perceived Ease of Use is the most important factor overall. This information could be uplifting to the software and system developers since it could directly influence positive changes in this factor. Search Ability, User Interface and Data Preservation are almost equally important factors overall and in the Perceived Ease of Use category with Search Ability and User Interface being the top two. Cost was a \#2 importance factor overall and \#1 in the External factors category. It was surprising to see Training being a less important factor in comparison to Cost. According to the expert judgments, Medical history (recording patients' health care information), Time Saving (reducing the time in terms of information gathering, viewing and searching the healthcare record information) and Quality of Care are more important subcriteria for Perceived Usefulness. All experts agreed that EHR adoption should be mandatory. The results of the calculations are displayed in the figure 7.

We have looked at EHR adoption trying to capture perceptions of doctors, although there are other stakeholders who may have different views on the importance of the criteria examined. For example, one might look at the perceptions of patients or hospital administrators or software developers.

The experts used in this study reflected the views of various hospitals and clinics in Portland Metro area. Such a study could be duplicated in other cities/geographic locations or could be conducted on a national level.

Administrators may have a better view of the external factors in the model and, therefore, more factors and their importance could be examined or a separate study on the influence of the external environment could be conducted.

TABLE 11: FINAL FACTOR WEIGHT RESULTS

\begin{tabular}{|c|c|c|c|}
\hline External Factors & Subcriteria Respectively & Results & \multicolumn{1}{|c}{ Cost } \\
\hline 0.27 & 0.41 & 0.1107 & Training \\
\hline 0.27 & 0.33 & 0.0891 & Legal Policy \\
\hline 0.27 & 0.26 & 0.0702 & \\
\hline
\end{tabular}

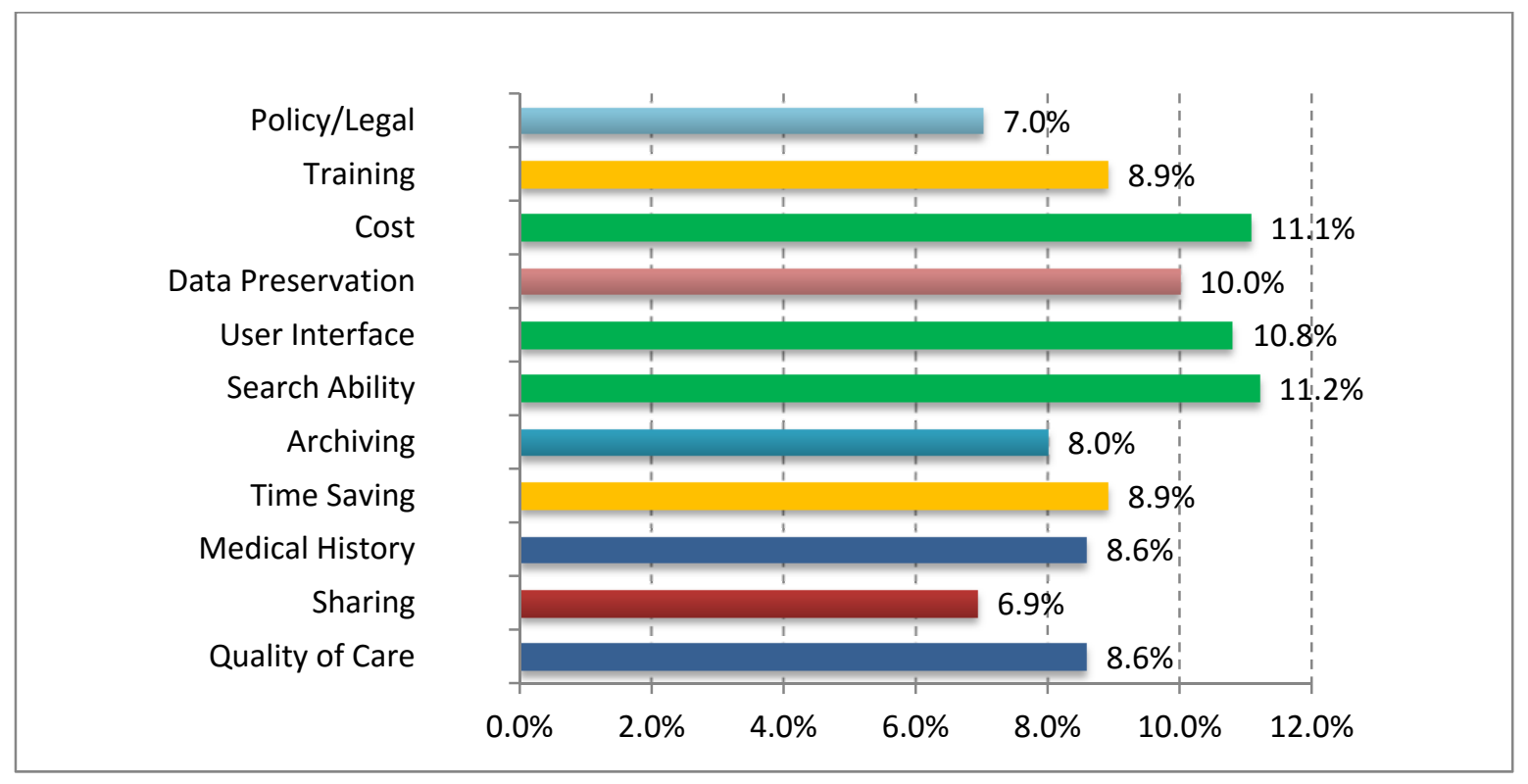

Figure 6: Distribution of all the subcriteria 


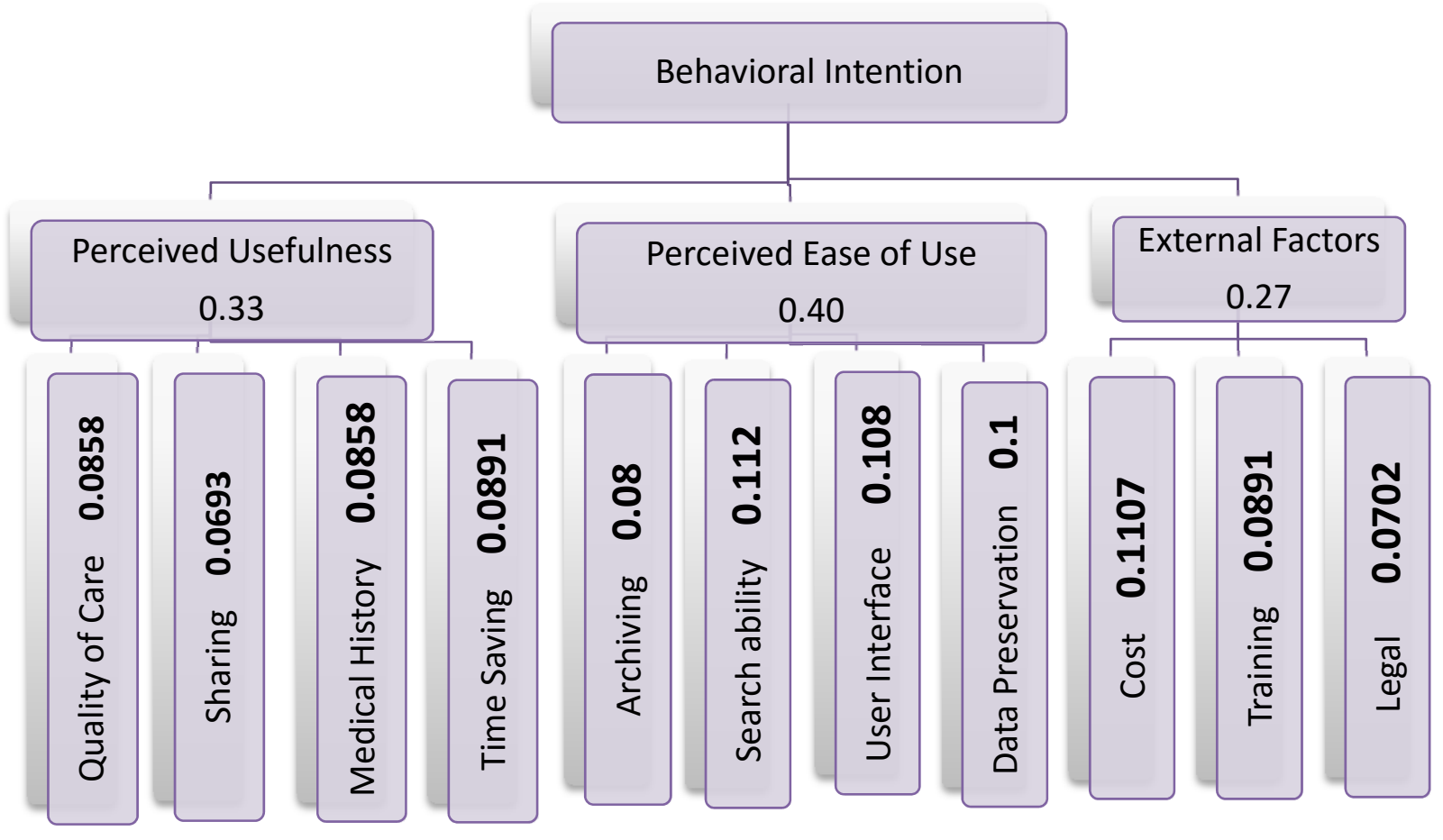

Figure 7: Summary of final results in the AHP model

It would be interesting to explore peer-to-peer and physician networks' influence on system adoption and try to incorporate those into the model since the literature [48], [49] shows that they have impacts on technology adoption.

The questionnaire gathered some information about the software used in the industry since the experts were asked to provide the names of the EHR system they were using at the time. Further research could be done to explore and evaluate those EHR systems.

It would be useful to extend this work using Roger's innovation diffusion theory as a basis for the AHP taxonomy as it is likely to represent a macro-perspective approach to this research. It would also be useful to explore innovativeness in the healthcare industry as part of EHR adoption research using this theory. Findings in this regard could positively influence the rate of adoption of this useful technology.

Employing TPB as a basis for the AHP taxonomy would be another beneficial extension of this research in order to incorporate perceived behavioral control as a determinant of behavioral intention. Additionally, UTAUT's incorporation of eight models in its development renders it another useful extension especially since validation found it to account for 70 percent of the variance in usage intention.

Further research is required to test whether or not the subcriteria impact other factors in the upper level. For instance, whether or not subcriteria under "perceived ease of use" affect "perceived usefulness and vice versa.

\section{REFERENCES}

[1] R. Shahpori, A. de los Angeles, and K. Laupland, "Information management framework: a model for clinical departments," Stud. Health Technol. Inform., vol. 143, pp. 81-86, 2009.

[2] Armstrong B. et al, "Technical and Architectural Issues in Deploying Electronic Health Records (EHRs) over the WWW," in Advances in information technology and communication in health, J. McDaniel, Ed. IOS Press, 2009, pp. 93-98.

[3] C. M. DesRoches and M. . Painter, "Health Information Technology in the United States : Moving Toward Meaningful Use," 2010.

[4] J. L. Tyler, "The healthcare information technology context: a framework for viewing legal aspects of telemedicine and teleradiology," in Proceedings of the 34th Annual Hawaii International Conference on System Sciences, 2001, p. 10.

[5] MGMA, "Electronic Health Records: Status, Needs and Lessons Electronic Health Records : Status, Needs and Lessons," 2011.

[6] C. Hsiao, E. Hing, and T. Socey, "Electronic Medical Record/Electronic Health Record Systems of Office-based Physicians: United States, 2009 and Preliminary 2010 State Estimates," 2010.

[7] D. M. Witter, Jr., J. Pettit, D. Nicholson, and T. Edlund, "Oregon Electronic Health Record Survey Ambulatory Practices and Clinics Fall $2006, " 2007$.

[8] B. Middleton, W. E. Hammond, P. F. Brennan, and G. F. Cooper, "Accelerating U.S. EHR adoption: how to get there from here. recommendations based on the 2004 ACMI retreat.," J. Am. Med. Inform. Assoc., vol. 12, no. 1, pp. 13-9, Jan. 2005.

[9] J. S. Ash, "Factors and Forces Affecting EHR System Adoption Report of a 2004 ACMI Discussion," J. Am. Med. Informatics Assoc. vol. 12 , no. 1 , pp. $8-12$, Oct. 2004

[10] E. T. Straub, "Understanding Technology Adoption: Theory and Future Directions for Informal Learning," Rev. Educ. Res., vol. 79, no. 2, pp. 625-649, Jun. 2009

[11] E. M. Rogers, Diffusion of Innovations, 4th ed. Simon and Schuster, 2010.

[12] M. Fishbein, "i Ajzen, I.(1975). Belief, Attitude, Intention, and 
Behaviour: An Introduction to Theory and Research," 1975.

[13] F. D. Davis, "A technology acceptance model for empirically testing new end-user information systems : theory and results." Massachusetts Institute of Technology, 1985.

[14] F. D. Davis, R. P. Bagozzi, and P. R. Warshaw, "User Acceptance of Computer Technology: A Comparison of Two Theoretical Models," Manage. Sci., vol. 35, no. 8, pp. 982-1003, Aug. 1989.

[15] V. Venkatesh and F. D. Davis, "A Theoretical Extension of the Technology Acceptance Model: Four Longitudinal Field Studies," Manage. Sci., vol. 46, no. 2, pp. 186-204, 2000.

[16] V. Venkatesh, M. G. Morris, G. B. Davis, and F. D. Davis, "User Acceptance of Information Technology: Toward a Unified View," MIS Q., vol. 27, no. 3, pp. 425-478, 2003.

[17] A. H. H. M. Mohamed, H. Tawfik, L. Norton, and D. Al-Jumeily, "eHTAM: A Technology Acceptance Model for electronic health," in 2011 International Conference on Innovations in Information Technology, 2011, pp. 134-138.

[18] Wen H.-C., Ho Y.-S., Jian W.-S., Li H.-C., and Hsu Y.-H.E., "Scientific production of electronic health record research, 1991-2005," Comput. Methods Programs Biomed., vol. 86, no. 2, pp. 191-196, 2007.

[19] S. J. Reiser, "The Clinical Record in Medicine Part 1: Learning from Cases," Ann. Intern. Med., vol. 114, no. 10, p. 902, May 1991.

[20] P. Tang and C. McDonald, "Electronic Health Record Systems," Biomed. Informatics, 2006.

[21] J. van Bemmel and M. Musen, Handbook of Medical Informatics. Springer, 1997

[22] National Institutes of Health National Center for Research Resources, "Electronic Health Records Overview," 2006.

[23] C. McDonald, "The Barriers to Electronic Medical Record Systems and How to Overcome Them," J. Am. Med. Informatics Assoc., vol. 4, no. 3, pp. 213-221, 1997.

[24] Gunter TD and Terry NP, "The Emergence of National Electronic Health Record Architectures in the United States and Australia: Models, Costs, and Questions," J Med Internet Res, vol. 7, no. 1, 2005.

[25] Ludwick D.A. and J. Doucette, "Adopting electronic medical records in primary care: Lessons learned from health information systems implementation experience in seven countries," Int. J. Med. Inform., vol. 78, no. 1, pp. 22-31, 2009 .

[26] O. Kök, N. Basoglu, and T. Dai, "Exploring the success factors of Electronic Health Record systems adoption," in ... in the Energy Smart World (PICMET ..., 2011, pp. 2943-2950.

[27] F. Davis, "Perceived usefulness, perceived ease of use, and user acceptance of information technology," MIS Q., 1989.

[28] M. Chuttur, "Overview of the Technology Acceptance Model: Origins , Developments and Future Directions," Bloomington, 9, 2009.

[29] P. Ruotsalainen, P. Doupi, and P. Hämäläinen, "Sharing and management of EHR data through a national archive: experiences from Finland.," World Hosp. Health Serv., vol. 43, no. 4, pp. 38-41, Jan. 2007.

[30] O. Kok, N. Basoglu, and T. Daim, "Exploring the Success Factors of Electronic Health Record Systems Adoption," in Portland International Center for Management of Engineering and Technology,
2011, pp. 2943-2950

[31] Anon, "BridgeHead Data Management Software and Data Domain Deduplication Storage for Healthcare Environments," Health Information Management Systems Society. [Online]. Available: http://www.datadomain.com/pdf/BridgeHead-DataDomain-HealthcareSolutionBrief.pdf.

[32] A. L. Comrey, "A proposed method for absolute ratio scaling," Psychometrika, vol. 15, no. 3, pp. 317-325, Sep. 1950.

[33] J. P. Guilford, Psychometric methods, 2nd ed. New York: McGraw Hill Book Company, INC., 1954.

[34] D. Kocaoglu, "A systems approach to the resource allocation process in police patrol.," University of Pittsburgh, 1976.

[35] L. Chan, "Developing a Strategic Policy Choice Framework for Sustainable Technological Innovation," Portland State University, 2013

[36] R. W. Saaty, "The analytic hierarchy process-what it is and how it is used," Math. Model., vol. 9, no. 3-5, pp. 161-176, Jan. 1987.

[37] O. S. Vaidya and S. Kumar, "Analytic hierarchy process: An overview of applications," Eur. J. Oper. Res., vol. 169, no. 1, pp. 1-29, Feb. 2006.

[38] M. Bertolini, M. Braglia, and G. Carmignani, "Application of the AHP methodology in making a proposal for a public work contract," Int. J. Proj. Manag., vol. 24, no. 5, pp. 422-430, Jul. 2006.

[39] D. F. Kocaoglu, "A participative approach to program evaluation," IEEE Trans. Eng. Manag., vol. EM-30, no. 3, pp. 112-118, 1983.

[40] Y. Lee and K. Kozar, "Investigating the effect of website quality on ebusiness success: An analytic hierarchy process (AHP) approach," Decis. Support Syst., vol. 42, no. 3, pp. 1383-1401, 2006.

[41] E. W. T. Ngai, "Selection of web sites for online advertising using the AHP," Inf. Manag., vol. 40, no. 4, pp. 233-242, Mar. 2003.

[42] G. Lockett, B. Hetherington, P. Yallup, M. Stratford, and B. Cox, "Modelling a Research Portfolio Using AHP: A Group Decision Process," R\&D Manag., vol. 16, no. 2, pp. 151-160, Apr. 1986.

[43] T. L. Saaty, "How to make a decision: The analytic hierarchy process," Eur. J. Oper. Res., vol. 48, no. 1, pp. 9-26, Sep. 1990.

[44] M. C. Carnero, "Selection of diagnostic techniques and instrumentation in a predictive maintenance program. A case study," Decis. Support Syst., vol. 38, no. 4, pp. 539-555, Jan. 2005.

[45] C.-J. Chen and C.-C. Huang, "A multiple criteria evaluation of hightech industries for the science-based industrial park in Taiwan," Inf. Manag., vol. 41, no. 7, pp. 839-851, Sep. 2004.

[46] J. Shang and T. Sueyoshi, "A unified framework for the selection of a Flexible Manufacturing System,” Eur. J. Oper. Res., vol. 85, no. 2, pp. 297-315, Sep. 1995.

[47] M. C. Y. Tam and R. V. M. Tummala, "An application of the AHP in vendor selection of a telecommunications system," Omega, vol. 29, no. 2, pp. 171-182, Apr. 2001.

[48] J. G. Anderson, C. E. Aydin, and S. J. Jay, Eds., Evaluating Health Care Information Systems: Methods and Applications. Sage Publications, Inc., 1994.

[49] K. Zheng, R. Padman, and M. P. Johnson, "Social contagion and technology adoption: a study in healthcare professionals.," AMIA Annu. Symp. Proc., p. 1175, Jan. 2007. 